DOI: $10.15593 / 2224-9982 / 2019.58 .01$

УДК 62-9

\author{
Е.В. Бояршинова, Р.В. Бульбович, Н.Л. Бачев
}

Пермский национальный исследовательский политехнический университет, Пермь, Россия

\author{
СИСТЕМА ОХЛАЖДЕНИЯ ВОЗДУШНО-КЕРОСИНОВОЙ ГОРЕЛКИ \\ В СОСТАВЕ УСТАНОВКИ ДЛЯ ИСПЫТАНИЙ ТЕРМОБАРЬЕРНЫХ \\ покрЫтий
}

\begin{abstract}
Для циклических испытаний термобарьерных покрытий требуется выокотемпературная газовая струя, температура которой должна быть не менее $1500 \stackrel{\circ}{\circ}$. Термодинамические расчеты показали, что указанные значения температуры можно обеспечить только при стехиометрическом горении углеводородных топлив, таких как керосин или природный газ. Для обеспечения необходимого ресурса работы высокотемпературного газогенератора требуется организация надежного охлаждения конструктивных элементов. Рассматривается вариант противоточного наружного охлаждения с использованием продольно-оребренной рубашки. Приводится подробная методика расчета системы охлаждения воздушно-керосиновой горелки, используемой в качестве основного элемента в составе установки для испытаний термобарьерных покрытий. Расчет значений температуры огневой стенки проводится итерационным методом до выполнения условия теплового баланса между горячими газами, стенкой и охладителем в каждом рассматриваемом сечении. Показано влияние геометрических размеров продольных ребер и рубашки охлаждения, а также коэффициента оребрения на температуру огневой стенки. Рассмотрены два варианта охладителей - вода и воздух. Приведены результаты расчетов разработанной модели, а также выполнен параметрический анализ вариантных расчетов системы охлаждения горелки, который позволил выбрать оптимальные геометрические параметры тракта охлаждения и охладитель. Подогретый воздух после рубашки охлаждения поступает непосредственно в зону горения газогенератора, где в полном объеме используется в качестве подогретого окислителя. Для дальнейших разработок рекомендуется воздушное охлаждение, которое является конструктивно более простым и экономически выгодным по сравнению с водяным охлаждением.

Ключевые слова: воздушно-керосиновая горелка, система охлаждения, температура стенки горелки, скорость охладителя, расход охладителя, расчетная модель, параметры системы охлаждения, параметры газа.
\end{abstract}

\author{
E.V. Boyarshinova, R.V. Bulbovich, N.L. Bachev
}

Perm National Research Polytechnic University, Perm, Russian Federation

\title{
COOLING SYSTEM OF THE AIR-KEROSENE BURNER IN THE COMPOSITION OF THE STAND FOR TESTING THERMO-BARRIER COATINGS
}

For cyclic tests of thermal barrier coatings, a high-temperature gas jet is required, the temperature of which must be at least $1500^{\circ} \mathrm{C}$. Thermodynamic calculations have shown that these temperatures can be provided only by stoichiometric combustion of hydrocarbon fuels such as kerosene or natural gas. To ensure the necessary service life of the high-temperature gas generator, it is necessary to organize reliable cooling of the structural elements. A variant of the counter-current external cooling, using a longitudinally-ribbed shirt. A detailed method of calculating the cooling system of the air-kerosene burner used as the main element in the installation for testing thermal barrier coatings is presented. The calculation of the temperature of the fire wall is carried out by the iterative method to meet the conditions of the thermal balance between the hot gases, the wall and the cooler in each section under consideration. The influence of the geometric dimensions of the longitudinal ribs and cooling jacket, as well as the finning coefficient on the temperature of the fire wall is shown. Two variants of coolers - water and air are considered. The results of calculations of the developed model are presented, as well as the parametric analysis of variant calculations of the burner cooling system, which allowed to choose the optimal geometric parameters of the cooling path and the cooler. The heated air after the cooling jacket enters directly into the combustion zone of the gas generator, where it is fully used as a heated oxidizer. For further development, air cooling is recommended, which is structurally simpler and more costeffective than water cooling.

Keywords: air-kerosene burner, cooling system, temperature burner wall, cooling speed, cooler consumption, calculation model, cooling system parameters, gas parameters. 
В настоящее время одной из основных задач увеличения ресурса современных газотурбинных установок является температурный режим работы турбинных лопаток. Для увеличения ресурса работы и КПД газотурбинного двигателя целесообразно применение термобарьерных покрытий на поверхностях конструкционных материалов. Циклические испытания таких покрытий предлагается проводить на стенде, где высокотемпературный газовый поток вырабатывается воздушно-керосиновой горелкой.

Для обеспечения длительного ресурса работы горелки необходима разработка надежной конструктивно простой системы охлаждения. В качестве охладителя в данной установке целесообразно применение воздуха либо воды по противоточной схеме. Воздух, нагретый в рубашке охлаждения, подается в горелку в качестве подогретого окислителя. При разработке системы охлаждения воздушно-керосиновой горелки использован принцип охлаждения стенки камеры сгорания жидкостных ракетных двигателей.

\section{Математическая модель}

На рис. 1 представлена расчетная схема охлаждения горелки, когда в качестве охладителя используется воздух. Для проведения расчетов системы охлаждения горелка была поделена на 20 секций по длине. Расчеты проводились для каждой секции отдельно по разработанной в Mathcad методике. Геометрические и режимные параметры горелки были определены в работе [1] по рекомендациям [2, 3].

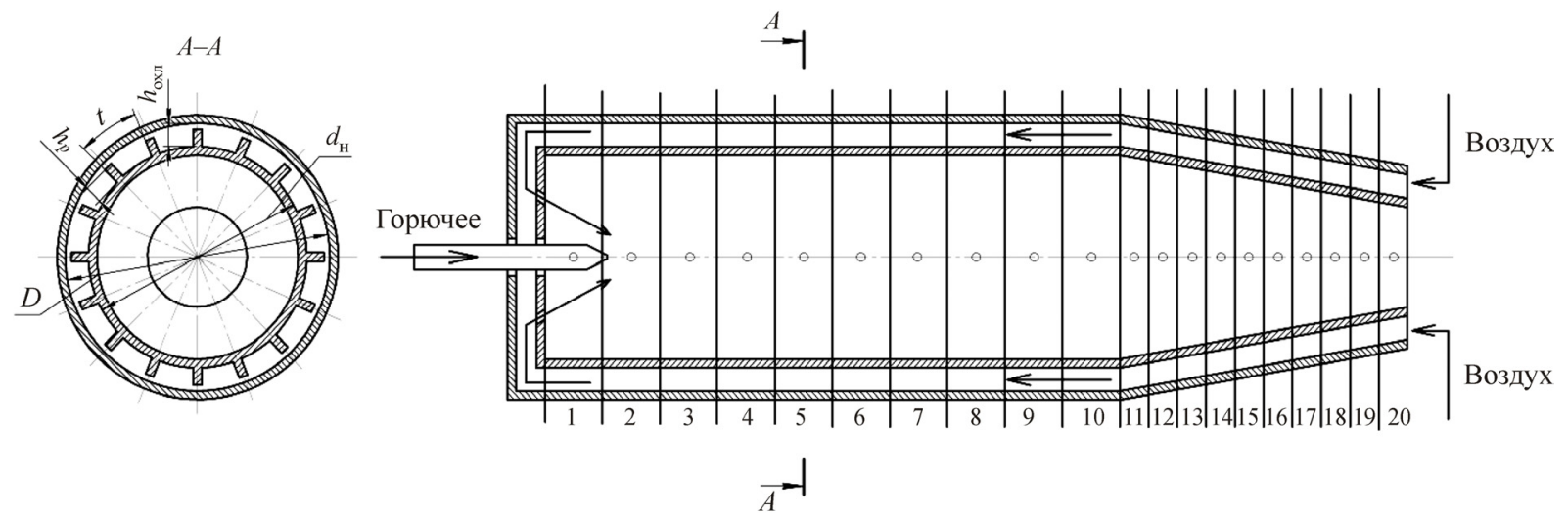

Рис. 1. Расчетная схема охлаждения горелки

Был разработан следующий алгоритм расчета системы охлаждения:

1. Определение приведенной скорости $q(\lambda)$ и газодинамических функций $\tau(\lambda), \pi(\lambda)[4,5]$.

По известным геометрическим параметрам определяется

$$
q(\lambda)=\frac{q\left(\lambda_{a}\right) d_{a}^{2}}{d^{2}}
$$

где $\lambda_{a}-$ приведенная скорость; $d_{a}$ - диаметр на срезе горелки; $d$ - диаметр горелки в данном сечении.

Приведенная скорость $\lambda$ по сечениям определяется из решения трансцендентного уравнения

$$
q(\lambda)=\left(\frac{k+1}{2}\right)^{\frac{1}{k-1}}\left(1-\frac{k-1}{k+1} \lambda^{2}\right)^{\frac{1}{k-1}} \cdot \lambda,
$$

где $k$ - показатель адиабаты; $\lambda$ - значение газодинамической функции в сечении. 


$$
\begin{gathered}
\tau(\lambda)=1-\frac{k-1}{k+1} \lambda^{2}, \\
\pi(\lambda)=\left(1-\frac{k-1}{k+1} \lambda^{2}\right)^{\frac{k}{k-1}} .
\end{gathered}
$$

2. Определение параметров газа в горелке по сечениям $[4,5]$ :

а) статическое давление

$$
P_{\Gamma}=P^{*} \pi(\lambda)
$$

где $P^{*}$ - полное давление в горелке;

б) статическая температура

где $T^{*}$ - температура ПС;

$$
T_{\Gamma}=T^{*} \tau(\lambda)
$$

в) критическая скорость

$$
a_{\text {кр }}=\sqrt{\frac{2 k}{k+1} R_{\mathrm{r}} T^{*}},
$$

где $R_{\Gamma}$ - газовая постоянная;

г) скорость продуктов сгорания

$$
W_{\text {г }}=\lambda_{a} a_{\text {кр }}
$$

д) статическая плотность

$$
\rho_{\Gamma}=\frac{P_{\Gamma}}{R T_{\Gamma}} .
$$

3. Подготовка данных по конвективному теплообмену между продуктами сгорания и стенкой $[6,7]$ :

а) критерий Прандтля газового потока

$$
\operatorname{Pr}_{\Gamma}=\frac{\mu_{\Gamma} C_{p \Gamma}}{\lambda_{\Gamma}},
$$

где $\mu_{г}-$ динамическая вязкость воздуха; $C_{p г}-$ удельная теплоемкость ПС; $\lambda_{г}-$ теплопроводность;

б) критерий Рейнольдса газового потока

$$
\operatorname{Re}_{\Gamma}=\frac{\rho_{\Gamma} W_{\Gamma} d_{\Gamma}}{\mu_{\Gamma}} ;
$$

в) критерий Нуссельта газового потока

$$
\mathrm{Nu}_{\Gamma}=0,023 \operatorname{Re}_{\Gamma}^{0,8} \operatorname{Pr}_{\Gamma}^{0,4}
$$

г) коэффициент теплообмена между газом и огневой стенкой

$$
\alpha_{\Gamma}=\lambda_{\Gamma} \frac{\mathrm{Nu}_{\Gamma}}{d} .
$$

4. Подготовка данных по лучистому теплообмену между продуктами сгорания и стенкой $[8,9]$ :

а) эффективная длина пути луча

$$
l_{\text {эф }}=\left(\frac{12 V}{\pi}\right)^{\frac{1}{3}} \text {, }
$$

где $V$ - объем горелки. 
б) парциальное давление углекислого газа

$$
P_{\mathrm{CO}_{2}}=r_{\mathrm{CO}_{2}} P^{*},
$$

где $r_{\mathrm{CO}_{2}}$ - объемная доля $\mathrm{CO}_{2}$ в составе продуктов сгорания;

в) парциальное давление паров воды

$$
P_{\mathrm{H}_{2} \mathrm{O}}=r_{\mathrm{H}_{2} \mathrm{O}} P^{*},
$$

где $r_{\mathrm{H}_{2} \mathrm{O}}$ - объемная доля $\mathrm{H}_{2} \mathrm{O}$ в составе продуктов сгорания;

г) степень черноты углекислого газа

$$
\varepsilon_{\mathrm{CO}_{2}}=0,71\left(P_{\mathrm{CO}_{2}} l_{\ni \phi}\right)^{0,33}\left(\frac{T^{*}}{100}\right)^{-0,5},
$$

где $\left[P_{\mathrm{CO}_{2}}\right]=$ атм, $\left[l_{\text {эф }}\right]=\mathrm{M},\left[T^{*}\right]=\mathrm{K}$;

д) степень черноты паров воды

$$
\varepsilon_{\mathrm{H}_{2} \mathrm{O}}=0,71\left(P_{\mathrm{H}_{2} \mathrm{O}} l_{\text {э中 }}\right)^{0,6} P^{* 0,2}\left(\frac{T^{*}}{100}\right)^{-1} ;
$$

е) степень черноты ПС

$$
\varepsilon_{\mathrm{r}}=\varepsilon_{\mathrm{CO}_{2}}+0,9 \varepsilon_{\mathrm{H}_{2} \mathrm{O}} .
$$

5. Расчет продольного оребрения в рубашке охлаждения [10, 11].

При проведении расчетов толщиной стенки, количеством ребер, высотой ребра и материалом горелки задаемся по имеющимся рекомендациям [12].

a) наружный диаметр огневой стенки

$$
d_{\mathrm{H}}=d+2 \delta_{\text {ст }},
$$

где $\delta_{\text {ст }}-$ толщина стенки;

б) шаг между ребрами

$$
t=\frac{\pi d_{\mathrm{H}}}{n_{\mathrm{p}}}
$$

где $n_{\mathrm{p}}-$ количество ребер;

в) расчет коэффициента оребрения:

$$
\psi=1+\frac{2 n_{\mathrm{p}} h_{\mathrm{p}}}{\pi d_{\mathrm{H}}},
$$

где $h_{\mathrm{p}}$ - высота ребра.

6. Расчет конвективных тепловых потоков между продуктами сгорания и огневой стенкой:

$$
q_{\mathrm{K}}=\alpha_{\Gamma}\left(T_{\text {г }}-T_{\text {стг }}\right),
$$

где $T_{\text {стг }}$ - температура огневой стенки со стороны газа.

7. Расчет лучистых тепловых потоков:

$$
q_{\text {л }}=\varepsilon_{\mathrm{r}} \varepsilon_{\mathrm{cr}} \sigma\left(T_{\mathrm{r}}^{4}-T_{\mathrm{cтг}}^{4}\right),
$$

где $\varepsilon_{\text {ст }}$ - степень черноты стенки; $\sigma$ - постоянная Стефана - Больцмана.

8. Расчет суммарных тепловых потоков:

$$
q=q_{\mathrm{K}}+q_{\mathrm{r}} .
$$


9. Расчет поверхности теплообмена

$$
S=\frac{\pi d_{\mathrm{H}} \Delta x}{\cos \beta},
$$

где $\Delta x$ - длина участка; $\beta$ - угол конфузорной части горелки.

10. Подготовка данных по конвективному теплообмену между охладителем и огневой стенкой:

а) давление охладителя на входе в рубашку $P_{\text {охл }}^{\text {вх }}$ определяется условием подачи охладителя;

б) температура охладителя на входе в рубашку охлаждения $T_{\text {охл }}^{\mathrm{Bx}}$ задается, если охладителем является вода, или рассчитывается, если охладитель - воздух:

$$
T_{\text {охл }}^{\mathrm{Bx}}=T_{0}\left(\frac{P_{\text {охл }}^{\mathrm{Bx}}}{P_{0}}\right)^{\frac{k-1}{k}},
$$

где $T_{0}, P_{0}$ - температура и давление охлаждающего воздуха;

в) подогрев охладителя на каждом участке

$$
\Delta T_{\text {охл }}=\frac{q S}{G_{\text {охл }} C_{\text {рохл }}} ;
$$

г) средняя температура охладителя по участкам

$$
T_{\text {охл }}=\frac{T_{\text {охл }}^{\mathrm{Bх}}+T_{\text {охл }}^{\text {вых }}}{2} ;
$$

д) при использовании в качестве охладителя воздуха теплофизические характеристики рассчитываются на каждом участке по следующим зависимостям (в системе СИ) [13, 14]:

- изобарная теплоемкость

$$
C_{\text {рохл }}=\left(1,0005+1,1904 \cdot 10^{-4}\left(T_{\text {охл }}-273\right)\right) \cdot 10^{3} ;
$$

- динамическая вязкость

$$
\mu_{\text {охл }}=1,717 \cdot 10^{-5}\left(\frac{T_{\text {охл }}}{273}\right)^{0,683}
$$

- теплопроводность

$$
\lambda_{\text {охл }}=2,44 \cdot 10^{-2}\left(\frac{T_{\text {охл }}}{273}\right)^{0,82} ;
$$

- плотность охладителя

$$
\rho_{\text {охл }}=\frac{P_{\text {охл }}^{\mathrm{вx}}+\Delta P_{\text {пот }}}{R_{\text {охл }} T_{\text {охл }}},
$$

где $\Delta P_{\text {пот }}-$ потери давления в рубашке охлаждения.

При использовании в качестве охладителя воды зависимость теплофизических характеристик от температуры не учитывается;

е) критерий Прандтля охладителя

$$
\operatorname{Pr}_{\text {охл }}=\frac{\mu_{\text {охл }} C_{\text {рохл }}}{\lambda_{\text {охл }}} .
$$


11. Геометрические параметры рубашки охлаждения:

а) наружный диаметр канала охлаждения

$$
D=d_{\text {н }}+2 h_{\text {охл }},
$$

где $h_{\text {охл }}$ - высота канала охлаждения;

б) площадь поверхности охлаждения

$$
F_{\text {охл }}=\frac{\pi\left(D^{2}-d_{\mathrm{r}}^{2}\right)}{4}-n_{\mathrm{p}} h_{\mathrm{p}} \delta_{\mathrm{p}} ;
$$

в) смоченный периметр

$$
\Pi=\pi D+\pi d_{\mathrm{H}}+2 n_{\mathrm{p}} h_{\mathrm{p}}
$$

г) эквивалентный диаметр

$$
d_{\text {экв }}=\frac{4 F_{\text {охл }}}{\Pi} .
$$

12. Скорости охладителя

$$
W_{\text {охл }}=\frac{G_{\text {охл }}}{\rho_{\text {охл }} F_{\text {охл }}} .
$$

13. Критерий Рейнольдса охладителя

$$
\operatorname{Re}_{\text {охл }}=\frac{\rho_{\text {охл }} W_{\text {охл }} d_{\text {экв }}}{\mu_{\text {охл }}} .
$$

14. Критерий Нуссельта

$$
\mathrm{Nu}_{\text {охл }}=0,023 \operatorname{Re}_{\text {охл }}^{0,8} \operatorname{Pr}_{\text {охл }}^{0,4} .
$$

15. Коэффициент теплообмена между огневой стенкой и охладителем

$$
\alpha_{\text {охл }}=\frac{\lambda_{\text {охл }} \mathrm{Nu}_{\text {охл }}}{d_{\text {экв }}} .
$$

16. Температура огневой стенки со стороны охладителя

$$
T_{\text {ст.охл }}=T_{\text {ст г }}-\frac{q \delta_{\text {охл }}}{\lambda_{\text {ст }}} .
$$

17. Тепловой поток из огневой стенки в охладитель

$$
q_{\text {ст.охл }}=\alpha_{\text {охл }}\left(T_{\text {ст.охл }}-T_{\text {охл }}\right) \psi .
$$

Расчет тепловых параметров производится методом последовательных приближений до выполнения теплового баланса [15]

с точностью до $0,1 \%$.

$$
q_{\text {стг }}=q_{\text {ст.охл }}
$$

\section{Результаты расчетов и их анализ}

Расчеты режимных и геометрических параметров системы охлаждения проводились для вариантов водяного и воздушного охлаждения.

В табл. 1 представлены основные результаты вариантных расчетов водяного охлаждения. 
Результаты вариантных расчетов водяного охлаждения горелки

\begin{tabular}{|c|c|c|c|c|c|c|c|c|c|}
\hline$n_{\mathrm{p}}$ & $t, \mathrm{M}$ & $\psi$ & $h_{\text {охл }}, \mathrm{M}$ & $h_{\mathrm{p}}, \mathrm{M}$ & $G_{\mathrm{H}_{2} \mathrm{O}}, \kappa \Gamma / \mathrm{c}$ & $\begin{array}{c}q_{\Sigma} \max \\
\mathrm{KBT}\end{array}$ & $\begin{array}{c}W_{\mathrm{r}} \max , \\
\mathrm{M} / \mathrm{c}\end{array}$ & $\begin{array}{c}W_{\text {охл }} \max , \\
\mathrm{M} / \mathrm{c}\end{array}$ & $\begin{array}{c}T_{\text {сг г }} \max , \\
\mathrm{K}\end{array}$ \\
\hline 10 & 0,027 & 1,7 & 0,015 & 0,01 & 0,1 & 902 & 482 & 0,044 & 1471 \\
\hline 10 & 0,027 & 1,7 & 0,015 & 0,01 & 0,220 & 1197 & 482 & 0,1 & 1205 \\
\hline 10 & 0,027 & 1,7 & 0,015 & 0,01 & 0,350 & 1351 & 482 & 0,156 & 1066 \\
\hline 10 & 0,027 & 1,7 & 0,015 & 0,01 & 0,5 & 1452 & 482 & 0,222 & 973 \\
\hline 0 & - & - & 0,015 & - & 0,5 & 975 & 482 & 0,204 & 1405 \\
\hline
\end{tabular}

В результате анализа данных табл. 1 предлагается наиболее оптимальный вариант водяного охлаждения: высота ребра $h_{\mathrm{p}}=0,01$; количество ребер $n_{\mathrm{p}}=10$; высота тракта охлаждения $h_{\text {охл }}=0,015$ м; расход охладителя (вода) $G_{\text {охл }}=0,350$ кг $/ \mathrm{c}$.

На рис. 2 представлены продольные профили параметров водяного охлаждения.

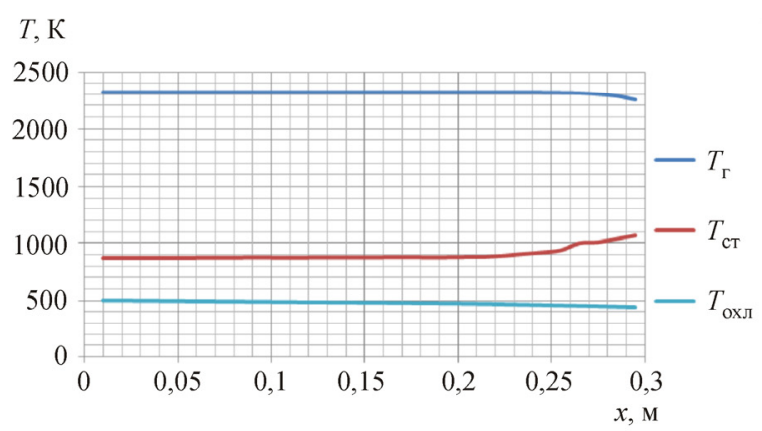

$a$

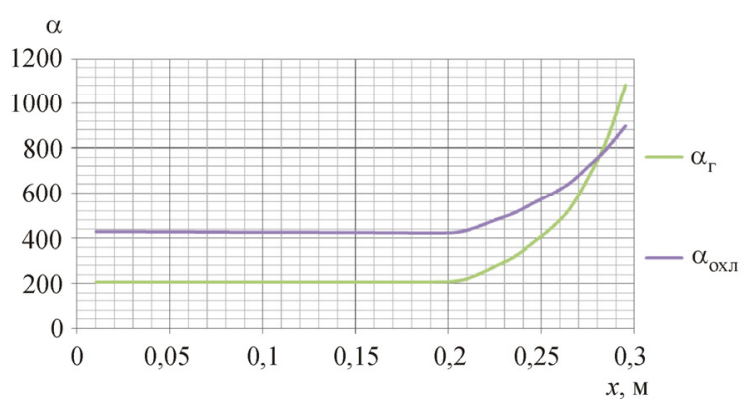

B

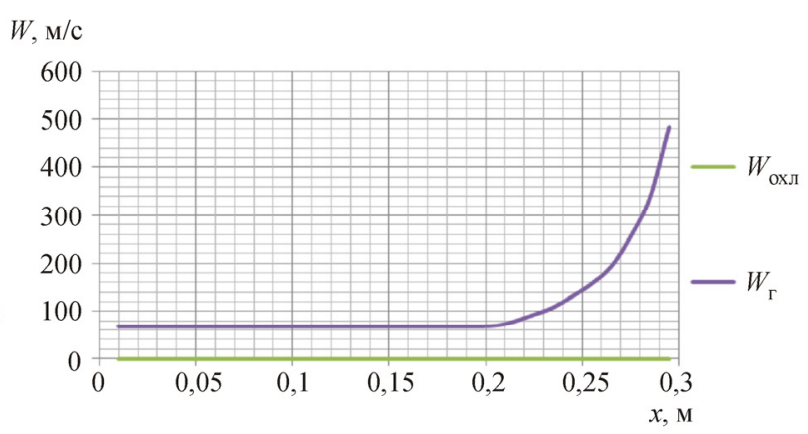

6

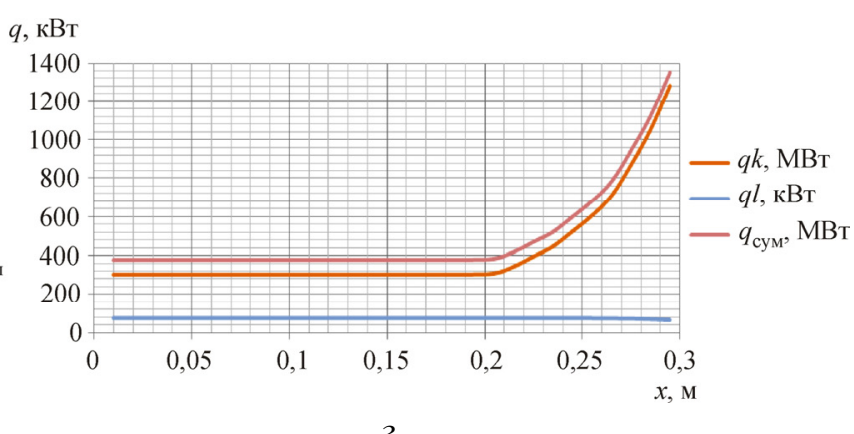

2

Рис. 2. Продольные профили параметров водяного охлаждения

Из графиков, представленных на рис. 2, можно сделать вывод о надежном охлаждении стенки горелки. Однако охлаждение водой требует дополнительного отвода нагретой воды, что ведет к усложнению конструкции, а следовательно, и к дополнительным затратам на подвод и отвод охлаждающей воды. в табл. 2.

Основные результаты вариантных расчетов воздушного охлаждения представлены

Анализ данных табл. 2 позволяет выбрать оптимальный вариант воздушного охлаждения со следующими параметрами: высота ребра $h_{\mathrm{p}}=0,005$ м; количество ребер $n_{\mathrm{p}}=20$; высота тракта охлаждения $h_{\text {охл }}=0,007$ м; расход охладителя (вода) $G_{\text {охл }}=0,220$ кг $/ \mathrm{c}$.

На рис. 3 приведены продольные профили параметров воздушного охлаждения. 
Таблица 2

Результаты расчетов воздушного охлаждения горелки

\begin{tabular}{|c|c|c|c|c|c|c|c|c|c|}
\hline$n_{\mathrm{p}}$ & $t, \mathrm{M}$ & $\psi$ & $h_{\text {охл }, ~ \mathrm{M}}$ & $h_{\mathrm{p}}, \mathrm{M}$ & $G_{\mathrm{H}_{2} \mathrm{O}}$, Кг/c & $\begin{array}{c}q_{\Sigma} \max , \\
\text { КВт }\end{array}$ & $\begin{array}{c}W_{\text {г }} \max , \\
\mathrm{M} / \mathrm{c}\end{array}$ & $\begin{array}{c}W_{\text {охл } \max ,}, \\
\mathrm{M} / \mathrm{c}\end{array}$ & $\begin{array}{c}T_{\text {сг г }} \max , \\
\mathrm{K}\end{array}$ \\
\hline 4 & 0,068 & 1,3 & 0,015 & 0,01 & 0,220 & 584 & 482 & 31,6 & 1753 \\
\hline 20 & 0,014 & 2,0 & 0,01 & 0,007 & 0,220 & 1212 & 482 & 61,6 & 1192 \\
\hline 20 & 0,014 & 1,7 & 0,007 & 0,005 & 0,220 & 1260 & 482 & 80,6 & 1089 \\
\hline 25 & 0,011 & 2,3 & 0,01 & 0,007 & 0,220 & 1302 & 482 & 65,6 & 1110 \\
\hline 25 & 0,011 & 2,8 & 0,015 & 0,01 & 0,220 & 1198 & 482 & 41,1 & 1205 \\
\hline 25 & 0,011 & 1,9 & 0,007 & 0,005 & 0,220 & 1309 & 482 & 98 & 1043 \\
\hline
\end{tabular}

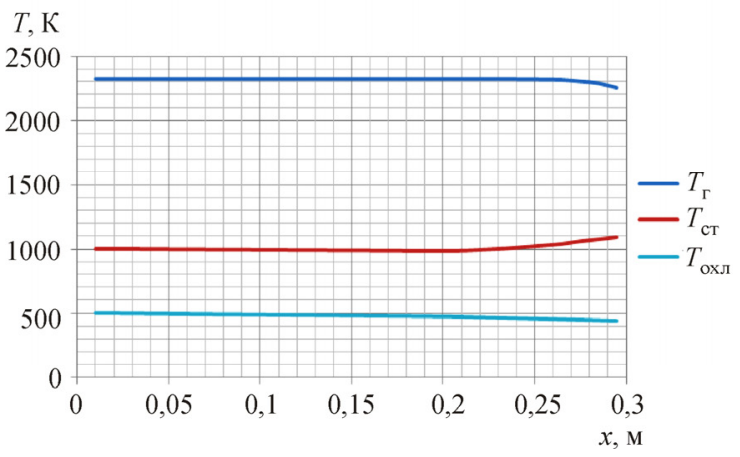

$a$

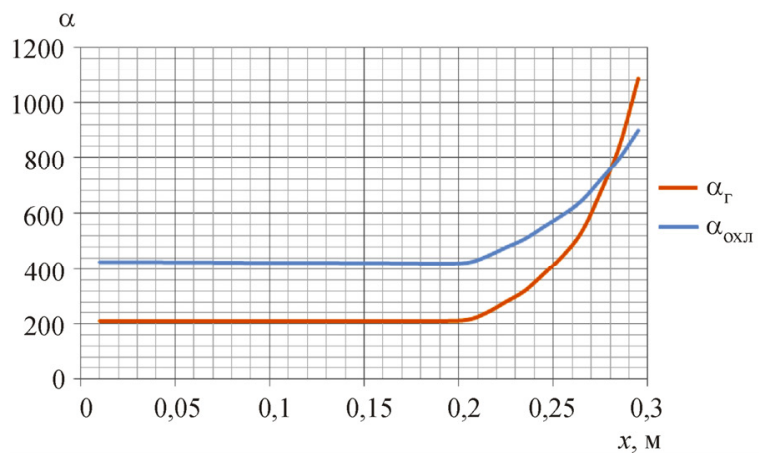

B

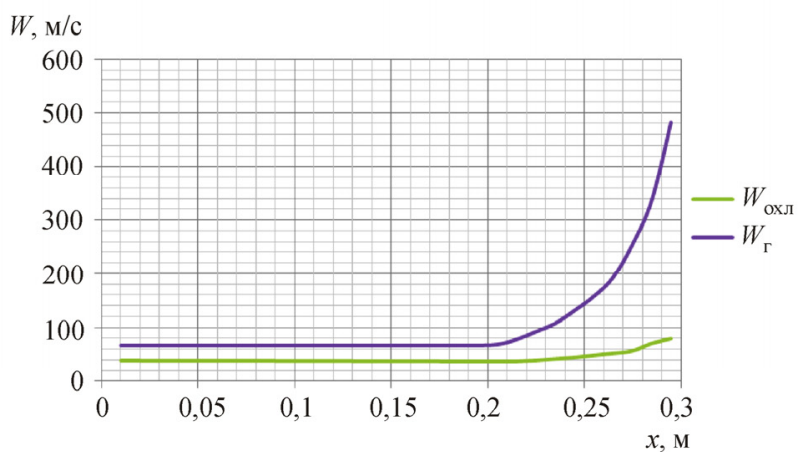

6

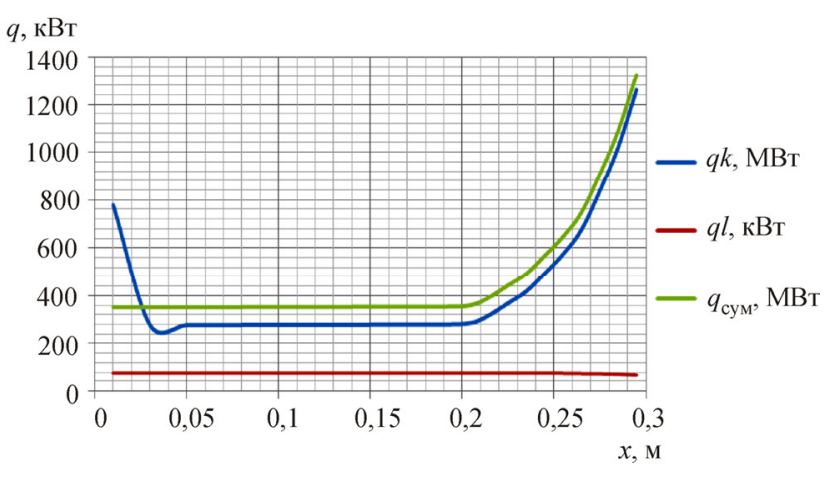

2

Рис. 3. Продольные профили параметров воздушного охлаждения

На рис. 3, $б$ видно, как происходит резкое увеличение скорости потока ПС за счет созданного конфузора. Скорость газов на выходе из горелки достигает 480 м/с, что соответствует требованиям ТЗ на разработку горелки. График скоростей также позволяет судить об отсутствии необходимости дополнительного сжатия воздуха на входе в горелку.

Графики, представленные на рис. $3, a$, позволяют говорить о надежном охлаждении огневой стенки. Температура огневой стенки поддерживается на уровне 1000 К, что говорит о возможности использования хромоникелевых сплавов в качестве конструкционного материала [16]. Кроме того, из данного графика можно судить о достаточности количества воздуха, используемого для обеспечения устойчивого горения в горелке, следовательно, дополнительного отвода охлаждающего воздуха не потребуется, что является несомненным достоинством данного варианта охлаждения. 
Увеличение скорости газового потока в конфузорной части горелки приводит к некоторому снижению температуры на выходе из горелки, увеличению коэффициента теплообмена $\alpha_{\text {г }}$

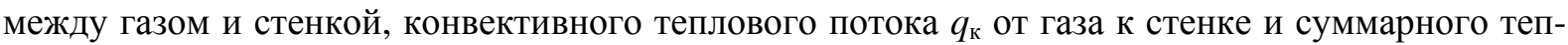
лового потока $q_{\Sigma}$ от газа к стенке, следовательно, к небольшому увеличению температуры стенки $T_{\text {ст }}$ со стороны газа.

Анализ данных табл. 2 показал также значительное влияние количества продольных ребер в рубашке охлаждения на температуру огневой стенки.

График зависимости температуры стенки газа от количества ребер приведен на рис. 4.

Таким образом, исследования показали, что температура огневой стенки сильно зависит от количества продольных ребер в рубашке, т.е. от коэффициента оребрения. Именно выбор оптимального оребрения позволяет в разрабатываемой

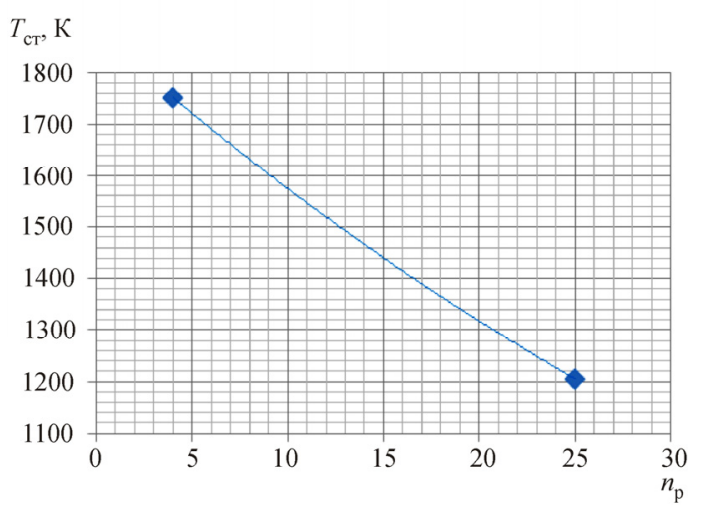

Рис. 4. График зависимости температуры стенки газа от количества ребер горелке обеспечить надежное охлаждение огневой стенки воздухом, что упрощает конструкцию блока охлаждения и не требует дополнительных расходов по подводу и отводу охлаждающей воды.

\section{Библиографический список}

1. Выбор геометрических и режимных параметров керосино-воздушной горелки в составе установки для испытаний термобарьерных покрытий / Е.В. Бояршинова, Н.Л. Бачев, О.О. Матюнин, Р.В. Бульбович // Вестник Пермского национального исследовательского политехнического университета. Аэрокосмическая техника. - 2017. - № 49. - С. 145.

2. Мингазов Б.Г. Камеры сгорания газотурбинных двигателей. - Казань: Изд-во Казан. гос. техн. ун-та, 2006. $-220 \mathrm{c}$.

3. Конструкция и проектирование жидкостных ракетных двигателей / Г.Г. Гахун [и др.]. М.: Машиностроение, 1989. - 424 с.

4. Газодинамические функции / Ю.Д. Иров [и др.]. - М.: Машиностроение, 1965. - 399 с.

5. Абрамович Г.Н. Прикладная газовая динамика. - М.: Наука, 1989. -824 с.

6. Кошкин В.К. Основы теплопередач в авиационной и ракетно-космической технике. - М.: Машиностроение, 1975. - $624 \mathrm{c}$.

7. Кутателадзе С.С. Основы теории теплообмена. - Новосибирск: Наука, 1970. - 659 с.

8. Сударев А.В., Антоновский В.И. Камеры сгорания газотурбинных установок. Теплообмен. Л.: Машиностроение, 1985. - 272 с.

9. Андриянов В.Н. Основы радиационного и сложного теплообмена. - М.: Энергия, 1972. -464 с.

10. Добровольский М.В. Жидкостные ракетные двигатели. - М. Изд-во Моск. гос. техн. ун-та им. Н.Э. Баумана, 2005. - 452 с.

11. Егорычев В.С. Термодинамический расчет и проектирование камеры сгорания ЖРД с СПК TERRA. - Самара: Изд-во Самар. гос. авиац. ун-та, 2013. - 107 с.

12. Основы конструирования авиационных двигателей и энергетических установок / А.А. Иноземцев [и др.]. - М.: Машиностроение, 2008. - Т. 2. - 368 с.

13. Алемасов В.Е., Дрегалин А.Ф., Черенков А.С. Основы теории физико-химических процессов в тепловых двигателях и энергетических установках. - М.: Химия, 2000. - 520 с.

14. Термодинамические и теплофизические свойства продуктов сгорания / В.Е. Алемасов, А.Ф. Дрегалин, А.П. Тишин, В.А. Худяков, В.Н. Костин; под ред. В.П. Глушко; ВИНИТИ. - М., 1973. T. 3. $-624 \mathrm{c}$.

15. Теплообмен в камере сгорания для утилизации попутного нефтяного газа / О.А. Зуева, Н.Л. Бачев, Р.В. Бульбович, А.М. Клещевников // Вестник Пермского национального исследовательского политехнического университета. Аэрокосмическая техника. - 2013. - № 34. - С. 52-63. 
16. Гольдштейн М.И., Грачев С.В., Векслер Ю.Г. Специальные стали. - М.: Металлургия, 1985. $408 \mathrm{c}$.

\section{References}

1. Boyarshinova E.V., Bachev N.L., Matyunin O.O., Bulbovich R.V. Vibor geometricheskih i regimnih parametrov kerosino-vozdushnoy gorelki v sostave ustanovki dlya ispitaniy termobariernih pokritiy [Selection of geometric and regime parameters of the kerosene-air burner in the composition of the stand for testing thermobarrier coatings]. PNRPU Aerospace Engineering Bulletin, 2017, no. 49, 145 p.

2. Mingazov B.G. Kamery sgoraniya gazoturbinnykh dvigateley [Combustion chambers of gas-turbine engines]. Kazan: Kazan State Technical University Publishing House, 2006, 220 p.

3. Gakhun G. G., etc. Konstruktsiya i proektirovanie zhidkostnykh raketnykh dvigateley [Design and design of liquid rocket engines]. - Moscow: Mashinostroenie, 1989. - $424 \mathrm{p}$.

4. Irov Yu.D., etc. Gazodinamicheskie funktsii [Gasdynamic functions], Moscow: Mashinostroenie, $1965,399 \mathrm{p}$.

5. Abramovich G.N. Prikladnaya gazovaya dinamika [Applied gas dynamics]. Moscow: Nauka, 1989, 824 p.

6. Koshkin V.K. Osnovi teploperedach v aviacionnoy i raketno-kosmicheskoy technike [Basics of heat transfer in aviation and rocket and space technology]. Moscow: Mashinostroenie, 1975, 624 p.

7. Kutateladze S.S. Osnovi teorii teploobmena [Basics of heat transfer theory]. Novosibirsk: Nauka, 1970, 659 p.

8. Sudarev A.V., Antonovsky V.I. Kamery sgoraniya gazoturbinnykh ustanovok. Teploobmen [Combustion chambers of gas-turbine installations. Heat exchange]. Leningrad: Mashinostroenie, 1985, $272 \mathrm{p}$.

9. Andriyanov V.N. Osnovi radiacionnogo i slognogo teploobmena [Basics of radiation and complex heat transfer]. Moscow: Energiya, 1972, 464 p.

10. Dobrovolskiy M.V. Gidkostnie raketnie dvigateli [Liquid rocket engines]. Moscow: Bauman Moscow State Technical University, 2005, 452 p.

11. Egorychev V.S. Termodinamicheskiy raschet i proektirovanie kamery sgoraniya ZhRD [Thermodynamic calculation and design of a combustion chamber of ZhRD]. Samara: Samara University Publishing House, 2013, 107 p.

12. Inozemtsev A.A., etc. Osnovy konstruirovaniya aviatsionnykh dvigateley i energeticheskikh ustanovok [Bases of designing of aviation engines and power stations]. Moscow: Mashinostroenie, 2008, vol. 2, 368 p.

13. Alemasov V.E., Dregalin A.F., Cherenkov A.S. Osnovy teorii fiziko-khimicheskikh protsessov v teplovykh dvigatelyakh i energeticheskikh ustanovkakh [Bases of the theory of physical and chemical processes in heat engines and power stations]. Moscow: Mashinostroenie, 2000, 520 p.

14. Alemasov V.E., Dregalin A.F., Tishin A.P., Khudyakov V.A., Kostin V.N. Termodinamicheskie i teplofizicheskie svoystva produktov sgoraniya [Thermodynamic and heatphysical properties of combustion materials]. Moscow: All-Russian Institute of Scientific and Technical Information RAS, 1973, vol. 3, 624 p.

15. Zueva O.A., Bachev N.L., Bulbovich R.V., Kleshevnikov A.M. Teploobmen v kamere sgoraniya dlya utilizacii poputnogo neftyanogo gasa [Heat exchange in the combustion chamber for utilization of associated petroleum gas]. PNRPU Aerospace Engineering Bulletin, 2013, no. 34, pp. 52-63.

16. Goldshtein M.I., Grachev S.V., Vexler U.G. Specialnie stali [Spesial steels]. Moscow: Metallurgiya, 1985,408 p.

\section{Сведения об авторах}

Бояршинова Екатерина Владимировна (Пермь, Россия) - аспирант кафедры «Ракетнокосмическая техника и энергетические системы» ФГБОУ ВО ПНИПУ (614990, г. Пермь, Комсомольский пр., д. 29, e-mail: katerinka_bev@mail.ru).

Бульбович Роман Васильевич (Пермь, Россия) - доктор технических наук, профессор кафедры «Ракетно-космическая техника и энергетические системы» ФГБОУ ВО ПНИПУ (614990, г. Пермь, Комсомольский пр., д. 29, e-mail: bulbovich@pstu.ru).

Бачев Николай Леонидович (Пермь, Россия) - кандидат технических наук, доцент кафедры «Ракетно-космическая техника и энергетические установки» ФГБОУ ВО ПНИПУ (614990, г. Пермь, Комсомольский пр., д. 29, e-mail: bn154@yandex.ru). 


\begin{abstract}
About the authors
Ekaterina V. Boyarshinova (Perm, Russian Federation) - PhD Student of Rocket and Space Technology, Generating Units Department, Perm National Research Polytechnic University (29, Komsomolsky av., Perm, 614990, Russian Federation, e-mail: katerinka_bev@mail.ru).

Roman V. Bulbovich (Perm, Russian Federation) - Doctor of Technical Sciences, Professor of Rocket and Space Technology, Generating Units Department, Perm National Research Polytechnic University (29, Komsomolsky av., Perm, 614990, Russian Federation, e-mail: bulbovich@ @stu.ru).

Nikolay L. Bachev (Perm, Russian Federation) - CSc in Technical Sciences, Associate Professor of Rocket and Space Technology, Generating Units Department, Perm National Research Polytechnic University (29, Komsomolsky av., Perm, 614990, Russian Federation, e-mail: bn154@yandex.ru).
\end{abstract}

Получено 07.05.2019 